\title{
Five-year Safety Data from 5 Clinical Trials of Subcutaneous Golimumab in Patients with Rheumatoid Arthritis, Psoriatic Arthritis, and Ankylosing Spondylitis
}

\author{
Jonathan Kay, Roy Fleischmann, Edward Keystone, Elizabeth C. Hsia, Benjamin Hsu, \\ Yiying Zhou, Neil Goldstein, and Jürgen Braun
}

ABSTRACT. Objective. Assess 5-year golimumab (GOL) safety in rheumatoid arthritis (RA), psoriatic arthritis (PsA), and ankylosing spondylitis (AS).

Methods. Subcutaneous (SC) GOL (50 mg or $100 \mathrm{mg}$ every 4 weeks) was evaluated in phase 3 trials of patients with active RA, PsA, and AS. Safety data through Year 5 were pooled across 3 RA trials [1 each evaluating methotrexate (MTX)-naive, MTX-experienced, and antitumor necrosis factor (TNF)-experienced patients], 1 PsA trial, and 1 AS trial. Data summarized was derived from both placebo-controlled (through weeks 24-52) and uncontrolled study periods. For adverse events (AE) of special interest [serious infections (SI), opportunistic infections (OI), deaths, malignancies, demyelination, tuberculosis (TB)], incidence per 100 patient-years (pt-yrs) was determined.

Results. Across all trials, 639 patients received placebo and 2228 received SC GOL $50 \mathrm{mg}$ only $(\mathrm{n}=$ $671), 50 \mathrm{mg}$ and $100 \mathrm{mg}(\mathrm{n}=765)$, or $100 \mathrm{mg}$ only $(\mathrm{n}=792)$. Safety followup extended for averages of 28.5 and 203.2 weeks for placebo and GOL, respectively. Respective placebo and GOL AE incidence/100 pt-yrs (95\% CI) through Year 5 were $4.86(2.83-7.78)$ and 3.29 (2.92-3.69) for SI, 0.00 $(0.00-0.86)$ and $0.23(0.14-0.35)$ for TB, $0.00(0.00-0.86)$ and $0.22(0.13-0.34)$ for OI, 0.00 $(0.00-0.86)$ and $0.10(0.05-0.20)$ for lymphoma, $0.00(0.00-0.86)$ and $0.08(0.03-0.17)$ for demyelination, and $0.29(0.01-1.59)$ and $0.41(0.29-0.57)$ for death. TB, OI, lymphoma, and demyelination incidence appeared to be higher among patients receiving GOL $100 \mathrm{mg}$ only.

Conclusion. SC GOL safety through Year 5 remained consistent with previously reported Year 3 findings and with other TNF antagonists. Numerically higher incidences of TB, OI, lymphoma, and demyelination were observed with $100 \mathrm{mg}$ versus $50 \mathrm{mg}$. Clinicaltrials.gov identifiers: NCT00264537 (GO-BEFORE), NCT00264550 (GO-FORWARD), NCT00299546 (GO-AFTER), NCT00265096 (GO-REVEAL), and NCT00265083 (GO-RAISE). (First Release November 1 2016; J Rheumatol 2016;43:2120-30; doi:10.3899/jrheum.160420)

\section{Key Indexing Terms: \\ ANTITUMOR NECROSIS FACTOR MALIGNANCY}

\section{CLINICAL TRIAL TUBERCULOSIS}

\section{ADVERSE EVENTS LYMPHOMA}

Golimumab (GOL) for subcutaneous (SC) injection is a human monoclonal antibody to tumor necrosis factor- $\alpha$ (TNF) that is approved for treating moderately to severely active rheumatoid arthritis (RA) in combination with methotrexate (MTX), active psoriatic arthritis (PsA) alone or in combination with MTX, active ankylosing spondylitis (AS), and moderate to severe active ulcerative colitis among patients with an inadequate response or intolerance to prior treatment or requiring continuous corticosteroid therapy. Across rheumatological indications, the approved SC GOL
From the Division of Rheumatology, Department of Medicine, UMass Memorial Medical Center, and University of Massachusetts Medical School, Worcester, Massachusetts; Rheumatology, University of Texas Southwestern Medical Center and Metroplex Clinical Research Center, Dallas, Texas; Janssen Research and Development LLC, Spring House; University of Pennsylvania, Philadelphia, Pennsylvania, USA; Division of Rheumatology, University of Toronto, Toronto, Ontario, Canada; Rheumatology, Rheumazentrum Ruhrgebeit, Herne, Germany.

J. Kay, MD, Division of Rheumatology, and Department of Medicine, UMass Memorial Medical Center, University of Massachusetts Medical School; R. Fleischmann, MD, Rheumatology, University of Texas

Southwestern Medical Center, and Metroplex Clinical Research Center; E. Keystone, $M D, F R C P(C)$, Division of Rheumatology, University of Toronto; E.C. Hsia, MD, Janssen Research and Development LLC, and
University of Pennsylvania; B. Hsu, $M D, P h D$, Janssen Research and Development LLC, and University of Pennsylvania; Y. Zhou, PhD, Janssen Research and Development LLC; N. Goldstein, MD, Janssen Research and Development LLC; J. Braun, MD, Rheumatology, Rheumazentrum Ruhrgebeit.

Address correspondence to Dr. J. Kay, Division of Rheumatology, Department of Medicine, UMass Memorial Medical Center and University of Massachusetts Medical School, Memorial Campus, 119 Belmont St., Worcester, Massachusetts 01605, USA. E-mail: jonathan.kay@umassmemorial.org

Full Release Article. For details see Reprints/Permissions at jrheum.org. Accepted for publication September 3, 2016.

Personal non-commercial use only. The Journal of Rheumatology Copyright @ 2016 . All rights reserved. 
dose is $50 \mathrm{mg}$ monthly; in Europe, a dose increase to $100 \mathrm{mg}$ monthly is approved for patients weighing more than $100 \mathrm{~kg}$ who do not respond to initial dosing ${ }^{1,2}$.

As a class, anti-TNF agents have a well-characterized and consistent safety profile across rheumatological indications and across agents, including adalimumab (ADA) $)^{3}$, certolizumab pegol ${ }^{4}$, etanercept $(\mathrm{ETN})^{5}$, and infliximab $(\mathrm{IFX})^{6}$. GOL safety through 3 years of treatment in the pivotal phase 3 trials of SC GOL in patients with RA, PsA, and $\mathrm{AS}^{7}$ appeared consistent with other TNF antagonists. The incidence of adverse events (AE) of special interest, including serious infections, demyelinating events, and lymphoma, appeared somewhat higher in patients receiving $100 \mathrm{mg}$ than in those receiving $50 \mathrm{mg}$ of GOL in the previous analysis ${ }^{7}$. These same randomized, double-blind, placebo-controlled trials included longterm extensions designed to evaluate SC GOL safety through 5 years of followup; these data are reported herein.

\section{MATERIALS AND METHODS}

Trials and patients. Our current study was a pooled analysis of previously collected safety data from 5 large multicenter trials ${ }^{8-17,18,19,20,21,22,23,24}$, each of which was conducted according to the Declaration of Helsinki and the International Committee on Harmonisation Good Clinical Practices. Each of the phase 3 study protocols was approved by central or individual site institutional review boards/ethics committees, and all patients provided written informed consent prior to any study-related procedures. No further ethical approval was required to conduct the additional data analyses reported herein. Patient entrance criteria and study designs for each trial have been reported ${ }^{8-17,18,19,20,21,22,23,24}$ and are summarized in Table 1. Additionally, further details of each trial are available at clinicaltrials.gov (GO-BEFORE: NCT00264537, GO-FORWARD: NCT00264550, GO-AFTER: NCT00299546, GO-REVEAL: NCT00265096, GO-RAISE: NCT00265083).

In brief, GO-BEFORE, GO-FORWARD, and GO-AFTER studies enrolled adults ( $\geq 18$ yrs) who had active RA ( $\geq 4$ swollen and $\geq 4$ tender joints) according to the revised 1987 American College of Rheumatology (formerly American Rheumatism Association) classification criteria ${ }^{25}$ for $\geq$ 3 months before the initial administration of study drug. In GO-BEFORE, patients with RA could not have received more than 3 weekly doses of oral MTX for RA. In GO-FORWARD, patients with RA must have been receiving MTX for $\geq 3$ months, with the dose being stable for $\geq 4$ weeks before the start of study treatment. In GO-AFTER, patients with RA must have received $\geq 1$ dose of an anti-TNF agent (ETN, ADA, or IFX), the last dose of which must have been given $\geq 8$ weeks (ADA or ETN) or $\geq 12$ weeks (IFX) before initiating study treatment.

Patients in the GO-REVEAL study were adults who had active PsA, defined by the presence of $\geq 3$ swollen and $\geq 3$ tender joints, despite treatment with disease-modifying antirheumatic drugs (DMARD) or nonsteroidal antiinflammatory drugs (NSAID); the absence of circulating rheumatoid factor; and the presence of a qualifying plaque psoriasis lesion $\geq 2 \mathrm{~cm}$ in diameter. Stable doses of MTX ( $\leq 25 \mathrm{mg} /$ week) were allowed, but not required.

Patients in the GO-RAISE study were adults who had active AS diagnosed according to the modified New York criteria ${ }^{26}$. Active AS was defined by a Bath AS Disease Activity Inde ${ }^{27}$ score $\geq 4$, a spinal pain assessment score $\geq 4$, and an inadequate response to NSAID and/or DMARD.

In all trials, eligible patients met the prespecified tuberculosis (TB) screening criteria. Patients with positive TB skin (per local criteria) and/or whole blood interferon-based QuantiFERON-TB Gold-In-Tube (Cellestis) testing results could participate, but had to begin treatment for latent TB before or with the first dose of study drug.

Data collection and analyses. All treated patients were included in these pooled safety analyses, as were all available followup data for patients who discontinued study agent for any reason. As reported ${ }^{7}, \mathrm{AE}$ were methodically documented and classified by the investigator for seriousness, intensity, causality, action taken, and whether the AE constituted an infection or an injection site reaction (ISR). AE were summarized by system organ class using the Medical Dictionary for Regulatory Activities, version 15.0, and reporting rates were pooled across the trials based on treatment received prior to the AE. Safety events from the first GOL exposure through the end of the 5-year followup period were included.

To provide an overview of longer-term GOL safety, occurrences of AE, serious adverse events (SAE), study drug discontinuation because of AE, infections, and ISR are summarized. To specifically assess AE of interest in the biologic treatment of patients with RA, PsA, and AS, incidence of death, serious infection, TB, opportunistic infection, malignancy, and demyelinating disorder was calculated as the number of events per 100 patient-years (pt-yrs) of followup, along with the corresponding exact 95\% CI. In analyses assessing incidence by year of study participation, placebo patients who had neither discontinued study participation nor received active drug at the beginning of the year-long interval were included. Each infection for an individual patient was counted separately. For malignancies, other than nonmelanoma skin cancer (NMSC), incidence was compared with that derived from an age-, sex-, and race-matched population from the 2007 US National Cancer Institute Surveillance, Epidemiology, and End Results (SEER) database ${ }^{28}$. In these analyses, standardized incidence ratios (SIR) with corresponding $95 \%$ CI were calculated by dividing the number of events observed in the GOL trials by the number of events that would have been expected based on the SEER database.

\section{RESULTS}

Across these 5 phase 3 trials of SC GOL, 639 patients received placebo and 2228 received GOL, including 671 receiving only the $50 \mathrm{mg}$ dose, 792 receiving only the 100 $\mathrm{mg}$ dose, and 765 receiving both GOL doses, yielding 8702 and 350 pt-yrs of followup for GOL and placebo, respectively (Table 2). Patients receiving both GOL $50 \mathrm{mg}$ and $100 \mathrm{mg}$ escaped early or had their GOL dose increased or decreased as outlined in Table 1. The majority of treated patients $(66.9 \%, 1537 / 2297)$ participated in 1 of the 3 RA trials (Figure 1); GOL exposure in this subgroup was generally similar to that observed among all patients (Table 2). Patient exposure through 5 years of followup has been reported for the individual $\mathrm{PsA}^{21}$ and $\mathrm{AS}^{24}$ trials.

The baseline patient demographics have been reported for each of the phase $3 \mathrm{RA}^{8,11,15}$, $\mathrm{PsA}^{18}$, and $\mathrm{AS}^{22}$ trials, and also in the 3-year pooled safety analysis of these trials ${ }^{7}$. About two-thirds of patients included in our pooled analysis had RA, while about $15 \%$ of patients each had PsA or AS.

Through 5 years of GOL treatment and followup, AE were reported by $73.6 \%, 92.8 \%, 92.0 \%$, and $95.5 \%$ of patients receiving placebo (mean followup 28.5 weeks), GOL $50 \mathrm{mg}$ only (184.0 weeks), GOL $50 \mathrm{mg}+100 \mathrm{mg}$ (227.5 weeks), and GOL $100 \mathrm{mg}$ only (195.9 weeks), respectively (Table 2 and Table 3). Common AE (i.e., those that occurred in $\geq 10 \%$ of patients in any treatment group) included infections, constitutional symptoms, hypertension (HTN), injection site erythema, and elevated alanine aminotransferase (ALT)

Personal non-commercial use only. The Journal of Rheumatology Copyright $\subset$ $(2016$. All rights reserved. 
Table 1. Pivotal phase 3 GOL trials contributing data to 5-year pooled safety analyses.

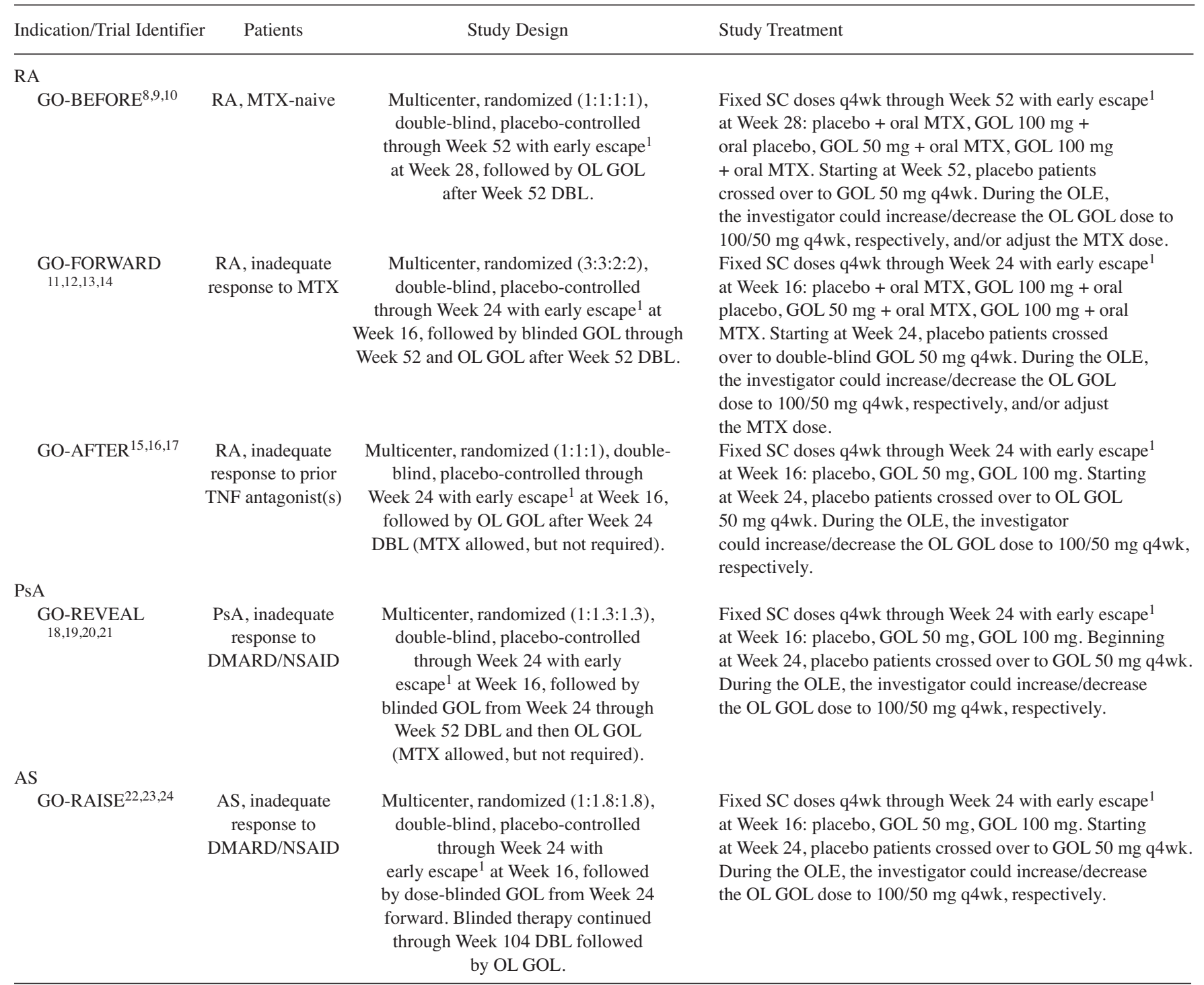

\footnotetext{
${ }^{1}$ For patients meeting the early escape criteria (i.e., $<20 \%$ improvement in tender and swollen joint counts for RA, $<10 \%$ improvement in tender and swollen joint counts for PsA, $<20 \%$ improvement in total back and morning stiffness for AS), those receiving placebo escaped to GOL $50 \mathrm{mg}$, those receiving GOL $100 \mathrm{mg}+$ placebo added MTX, those receiving GOL $50 \mathrm{mg}$ increased the GOL dose to $100 \mathrm{mg}$, and those receiving GOL $100 \mathrm{mg}$ had no change in study medication. GOL: golimumab; RA: rheumatoid arthritis; MTX: methotrexate; TNF: tumor necrosis factor; PsA: psoriatic arthritis; DMARD: disease-modifying antirheumatic drug; NSAID: nonsteroidal antiinflammatory drug; AS: ankylosing spondylitis, OL: open label; DBL: database lock; q4wk: every 4 weeks; OLE: open-label extension; SC: subcutaneous.
}

levels (Table 3). Although a larger proportion of GOL-treated patients $(9.9 \%)$ had a serious infection during study participation than did placebo-treated patients $(2.7 \%)$, the incidence of serious infection was comparable between combined GOL (3.29/100 pt-yrs) and placebo (4.86/100 pt-yrs) treatment when adjusted for length of followup. The incidence of serious infections did not appear to increase with the duration of GOL treatment (Table 4). Findings were consistent among the patients in the safety database with RA (Table 5).

Greater incidence of active TB (0.30 vs $0.17 / 100$ pt-yrs) and opportunistic infections ( 0.37 vs $0.13 / 100$ pt-yrs) was observed for the GOL $100 \mathrm{mg}$ only group than for the GOL $50 \mathrm{mg}$ only group; the $95 \% \mathrm{CI}$ for both GOL doses, however, were contained within those for placebo for both of these AE through 5 years of GOL treatment. The 18 patients with opportunistic infection included 13 with RA (6 with esophageal/gastrointestinal candidiasis; 2 with histoplasmosis; and 1 each with aspergilloma, esophageal candidiasis/ aspergillosis, Pneumocystis jirovecii pneumonia, Pneumonia legionella, and ophthalmic herpes zoster), 3 with PsA (toxoplasmal eye infection, histoplasmosis, P. legionella), and 2 with AS (coccidioidomycosis, cryptosporidiosis). 
Table 2. Extent of exposure and followup through 5 years: pooled data across 5 phase 3 studies of SC GOL (with or without MTX) in RA (3 trials), PsA (1 trial), and AS (1 trial). Values are mean/median unless stated otherwise.

\begin{tabular}{|c|c|c|c|c|c|}
\hline Variables & Placebo & GOL 50 mg Only & GOL 50 and $100 \mathrm{mg}$ & GOL 100 mg Only & GOL Combined \\
\hline \multicolumn{6}{|l|}{5 trials: 3 RA, 1 PsA, 1 AS } \\
\hline No. treated patients ${ }^{1}$ & 639 & 671 & 765 & 792 & 2228 \\
\hline No. SC injections & $6.6 / 6.0$ & $42.6 / 57.0$ & $52.9 / 60.0$ & $45.3 / 61.0$ & $47.1 / 58.0$ \\
\hline Weeks of safety followup ${ }^{2}$ & $28.5 / 24.0$ & $184.0 / 240.1$ & $227.5 / 255.7$ & $195.9 / 257.3$ & $203.2 / 252.4$ \\
\hline Total patient-yrs of followup & 350 & 2374 & 3346 & 2982 & 8702 \\
\hline Cumulative GOL dose, mg & $0.0 / 0.0$ & $2132 / 2850$ & $4376 / 4850$ & $4525 / 6100$ & $3753 / 3600$ \\
\hline \multicolumn{6}{|l|}{3 RA trials } \\
\hline No. treated patients ${ }^{1}$ & 449 & 374 & 542 & 565 & 1481 \\
\hline No. SC injections & $7.4 / 6.0$ & $39.4 / 51.0$ & $51.5 / 58.0$ & $43.2 / 60.0$ & $45.3 / 57.0$ \\
\hline Weeks of safety followup ${ }^{2}$ & $32.2 / 24.0$ & $172.0 / 216.3$ & $223.0 / 252.1$ & $188.3 / 257.0$ & $196.9 / 244.9$ \\
\hline Total patient-yrs of followup & 278 & 1237 & 2323 & 2044 & 5604 \\
\hline Cumulative GOL dose, mg & $0.0 / 0.0$ & $1967 / 2525$ & $4242 / 4625$ & $4318 / 6000$ & $3697 / 3650$ \\
\hline
\end{tabular}

\footnotetext{
${ }^{1}$ Note that some patients received placebo followed by GOL in early escape or following crossover per trial design. ${ }^{2}$ Including posttreatment followup. SC: subcutaneous; GOL: golimumab; MTX: methotrexate; RA: rheumatoid arthritis; PsA: psoriatic arthritis; AS: ankylosing spondylitis.
}

Patients with TB, including 18 with RA, 1 with PsA, and 1 with AS, resided in Asia $(n=12)$, Europe $(n=6)$, and South America $(n=2)$. No increase in the occurrence of either active TB or opportunistic infection was observed over time (Table 4).

Through 5 years, with a much longer period of followup for GOL than for placebo treatment, 58 (9.1\%), 177 (26.4\%), $230(30.1 \%)$, and 275 patients $(34.7 \%)$ in the placebo, GOL $50 \mathrm{mg}$ only, GOL $50 \mathrm{mg}+100 \mathrm{mg}$, and GOL $100 \mathrm{mg}$ only groups, respectively, had $\geq 1 \mathrm{SAE}$, and 33 (5.2\%), 103 $(15.4 \%), 73(9.5 \%)$, and $158(19.9 \%)$ patients, respectively, discontinued the study drug because of an AE (Table 3). Through 5 years, 37 patients died, including $1(0.2 \%), 11$ $(1.6 \%), 9(1.2 \%)$, and 16 patients $(2.0 \%)$ in the placebo, GOL $50 \mathrm{mg}$ only, GOL $50 \mathrm{mg}+100 \mathrm{mg}$, and GOL $100 \mathrm{mg}$ only groups, respectively. The time-adjusted incidence of death was $0.29 / 100$ pt-yrs for the placebo-controlled period and $0.41 / 100$ pt-yrs through 5 years for patients who received GOL (Table 4), the 95\% CI for which, however, was contained within that for placebo. The incidence of death appeared to be stable over time (Table 4). Among the 37 deaths, 8 occurred within the first year, 12 occurred during the second and third years, and 17 occurred during the fourth and fifth years of study participation. Four patients whose duration of followup could not be determined were not included in Table 4. Causes of death were malignancy in 13 patients, infection in 8 patients, cerebrovascular/cardiovascular event in 7 patients, an unrelated accident in each of 2 patients, hypoglycemic coma in 1 patient following a suicide attempt, hepatitis in 1 patient, and an overdose of tramadol in 1 patient; the cause of death was not known for 4 patients.

The overall time-adjusted incidence of malignancy through 5 years did not appear to be elevated with GOL versus placebo treatment (1.07 vs 2.59/100 pt-yrs, respectively) or when compared with rates expected in the general US population (SIR 1.08, 95\% CI 0.82-1.40); similar findings were observed for NMSC (Table 4). A higher incidence of lymphoma relative to the general US population was observed through 5 years among patients who had received GOL $100 \mathrm{mg}$ only (SIR 7.71, 95\% CI 2.83-16.78, not inclusive of 1). This higher incidence of lymphoma among patients who received only GOL $100 \mathrm{mg}$ led to a higher incidence of lymphoma among all GOL-treated patients relative to the general US population (SIR 3.89, 95\% CI 1.78-7.38). Conversely, the 95\% CI surrounding the SIR for lymphoma among patients who received GOL $50 \mathrm{mg}$ only, i.e., 1.71 (0.04-9.50), was inclusive of 1 (Table 4). Patients with RA mostly drove this higher incidence of lymphoma (Table 5). Among the 9 patients with lymphoma, 8 had RA that ranged in duration from 4.7 to 31.4 years (mean $12.7 \mathrm{yrs}$ ). Of the 8 patients with RA, 4 had previously responded inadequately to another TNF inhibitor, 3 had a family history of cancer, and 2 tested positive for Epstein-Barr virus (EBV). These 8 patients, all of whom received GOL $100 \mathrm{mg}$ during study participation, had 28-joint Disease Activity Scores based on C-reactive protein (DAS28-CRP) that ranged from 4.8 to 7.9 (mean 6.3) at study onset and from 1.8 to 6.6 (mean 4.0 ) at the study visit closest to the time of lymphoma diagnosis (Supplementary Table 1, available online at jrheum.org).

No increase in the occurrence of any malignancy, NMSC, or lymphoma was observed with longer duration of GOL treatment (Table 4). Consistent findings were observed among the subgroups of patients with RA (Table 5).

Through 5 years, demyelination events were reported in 7 patients, including 2 patients with AS (chronic inflammatory demyelinating polyneuropathy, multiple sclerosis) and 5 patients with RA (sclerosis multiplex, demyelination of the central nervous system, autoimmune demyelination, cervical spine lesion/not disc disease/suspected demyelinating process, demyelinating areas of brain). All patients had received GOL $100 \mathrm{mg}$ prior to the event. The highest incidence of demyeli-

$$
\text { Personal non-commercial use only. The Journal of Rheumatology Copyright () 2016. All rights reserved. }
$$




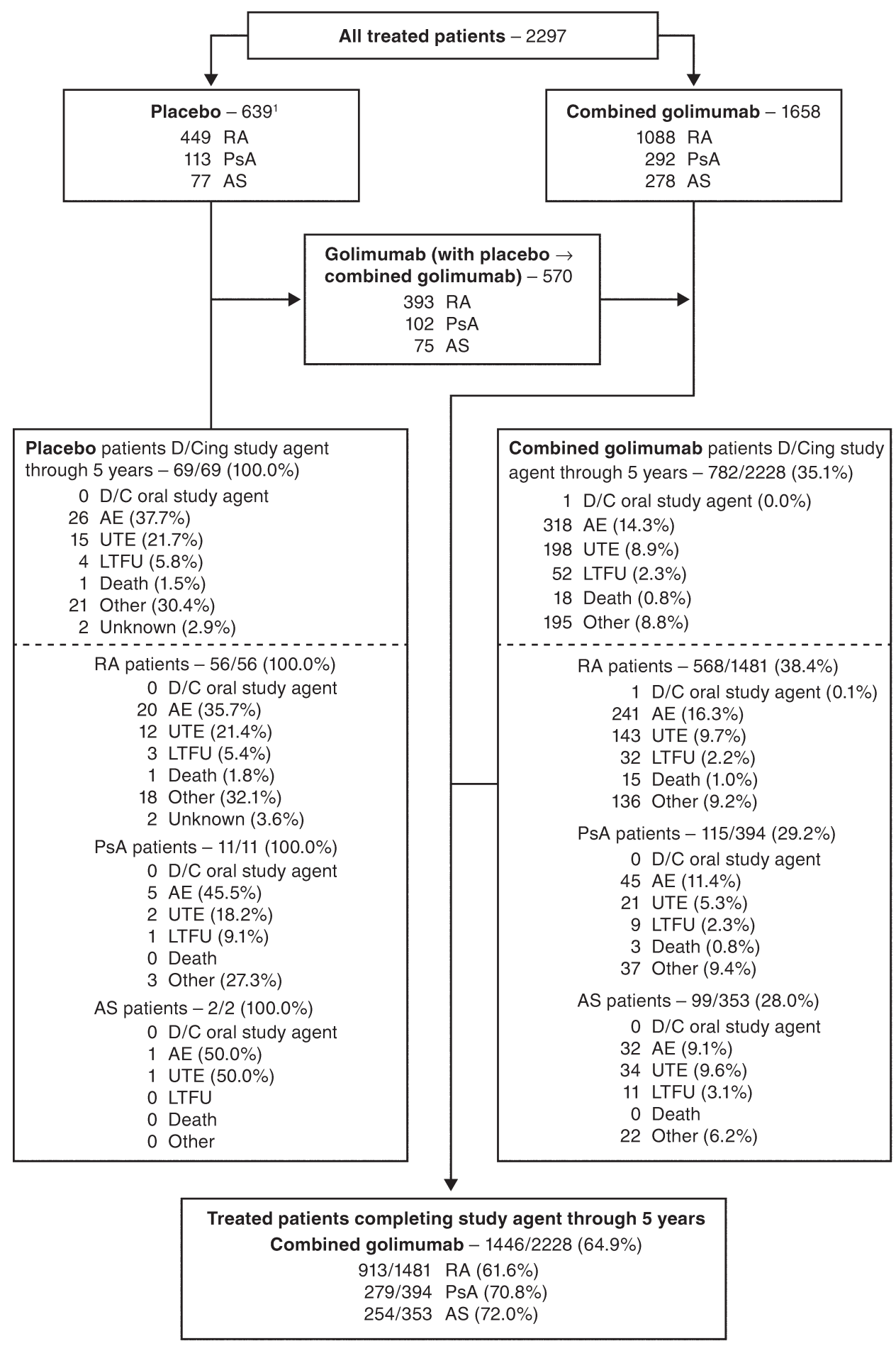

Figure 1. Patient disposition through 5 years of 5 phase 3 clinical trials of subcutaneous golimumab in rheumatological indications. ${ }^{1}$ Some patients received placebo followed by golimumab in early escape or following crossover per trial design. RA: rheumatoid arthritis; PsA: psoriatic arthritis; AS: ankylosing spondylitis; D/C: discontinued; AE: adverse event; UTE: unsatisfactory therapeutic effect; LTFU: lost to followup.

nation was observed during the fourth year of GOL treatment $(0.19 / 100 \mathrm{pt}-\mathrm{yrs})$, although during the fifth year $(0.06 / 100$ pt-yrs) the incidence was similar to that observed in each of the first 3 years $(0.05-0.06 / 100 \mathrm{pt}-\mathrm{yrs})$. Overall, the highest incidence of demyelination over 5 years was observed among patients who received GOL $100 \mathrm{mg}$ only, i.e., $0.20 / 100$ pt-yrs; 
Table 3. Safety findings through 5 years: pooled data from phase 3 studies of SC GOL (with or without MTX) in rheumatological indications. Values are n (\%) or $\mathrm{n} / \mathrm{N}(\%)$ of patients.

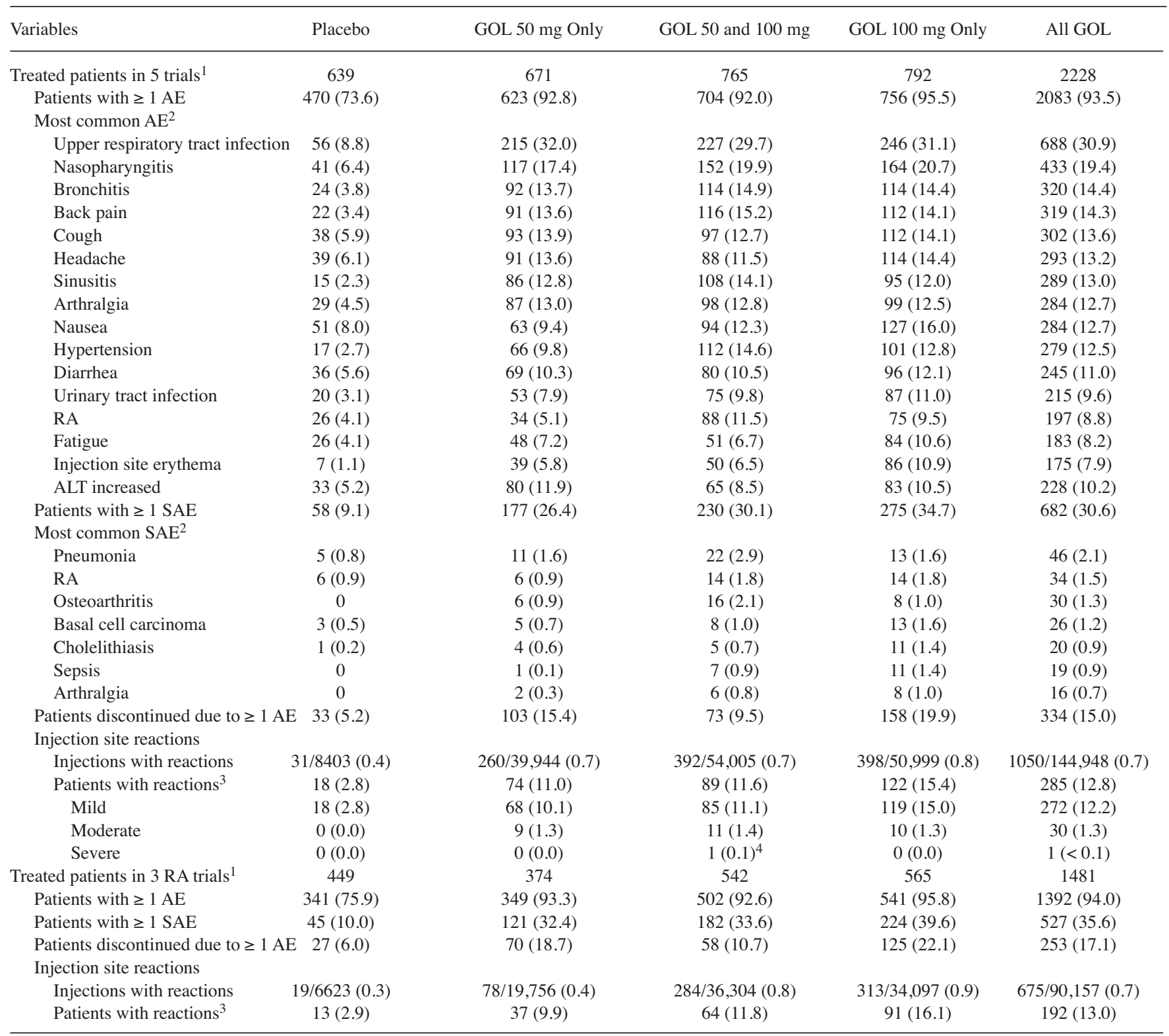

${ }^{1}$ Note that some patients received placebo followed by GOL in early escape or following crossover per trial design. ${ }^{2}$ Defined as AE and SAE occurring in $\geq$ $10 \%$ and $\geq 1 \%$, respectively, of patients in any treatment group. Common AE and SAE are presented in decreasing order of frequency in the GOL combined group. ${ }^{3}$ Patients may have reported $\geq 1$ injection reaction. ${ }^{4}$ A serious event of erythema on the thigh in a patient with early RA receiving GOL $100 \mathrm{mg}$ at the time of the reaction (Day 368). SC: subcutaneous; GOL: golimumab; MTX: methotrexate; AE: adverse event; ALT: alanine aminotransferase; SAE: serious AE; RA: rheumatoid arthritis.

the surrounding $95 \% \mathrm{CI}(0.07-0.44)$, however, was contained within that for placebo (Table 4).

The proportions of patients with an ISR were $12.8 \%$ for GOL and $2.8 \%$ for placebo, and the proportions of injections that resulted in an ISR were $0.7 \%$ for GOL and $0.4 \%$ for placebo (Table 3). Only 1 patient discontinued study drug because of an ISR. This patient received GOL $100 \mathrm{mg}$ plus MTX and had detectable antibodies to $\mathrm{GOL}^{7}$.

\section{DISCUSSION}

We pooled safety data through 5 years across 5 phase 3 trials of patients with active RA, PsA, and AS who were treated with SC GOL (50 mg or $100 \mathrm{mg}$ every 4 weeks). The 5 trials, consisting of 3 studies in patients with RA (1 each in MTX-naive, MTX-experienced, and anti-TNF-experienced patients), 1 in patients with PsA, and 1 in patients with AS, included both placebo-controlled (extending from Week 0

Personal non-commercial use only. The Journal of Rheumatology Copyright $\odot$ 2016. All rights reserved. 


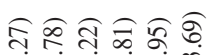

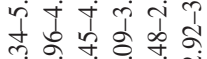

cid d a d

สิণ

ते $\overrightarrow{0} \hat{\sigma} \vec{\sigma}$

cid

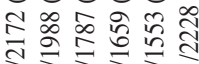

공

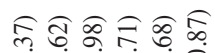

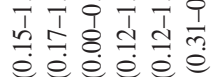

药

กิ तो

èe éd

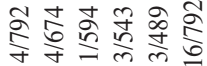

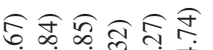

等

ذd d

눙 \&

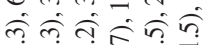

जल

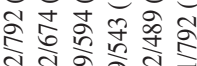

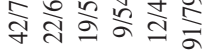

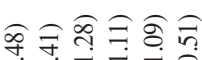

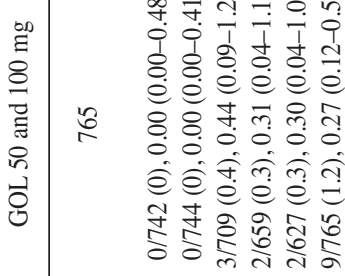

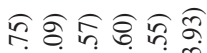

पि की प को

สำ 우 궁

¿ d

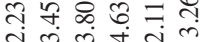

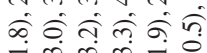

¿ ल

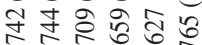

ल ন শ্ন

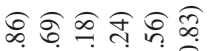

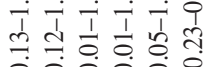

tejese

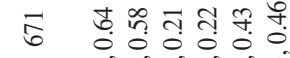

की

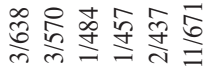

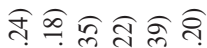

की

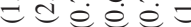

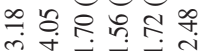

के कि

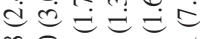

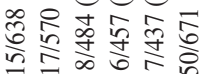

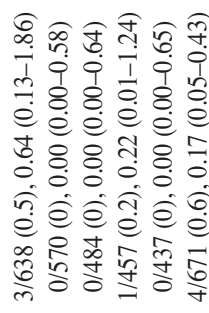

๙ิ귀

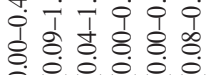

구의

80.000

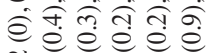

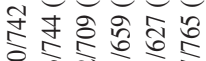

के क्षे क्षे

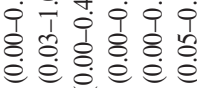

워의는

000000

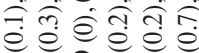

寺考合藏

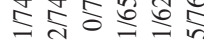

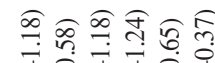

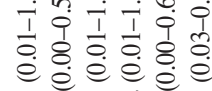

तิ

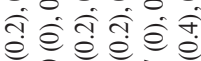

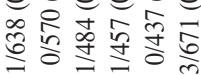

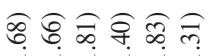

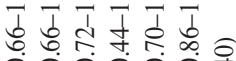

eेe巳巳e巳e

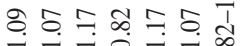

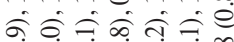

e $\dot{0} \doteq$

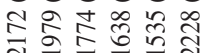

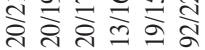

合在吉在

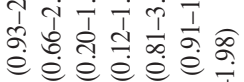

e e e e e

- - o. -

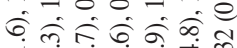

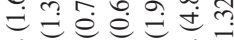

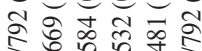

高年等

으조ำิ สิ

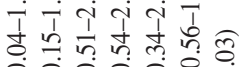

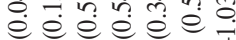

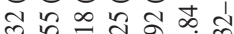

$00-1000$

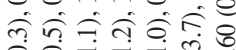

e $= \pm \doteq$

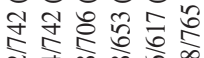

त年办为

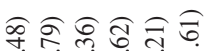

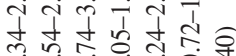

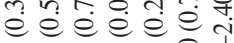

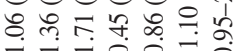

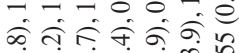

e己巳巳e

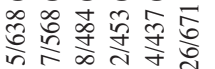

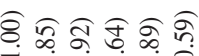

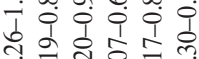

eे巳e

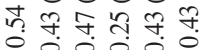

के ने त़े

èe és

드용ำ

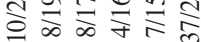

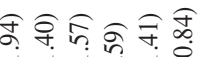

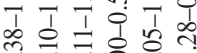

eे巳 e. e

분 8 ले ज़

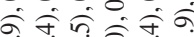

eेe e

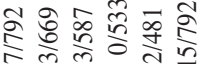

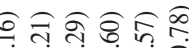

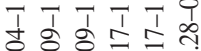

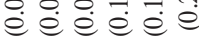

舟讨孝

0000

+ 60.

भ

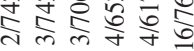

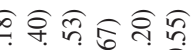

1 1 t)

èं $\dot{e} \dot{e}$

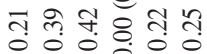

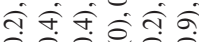

ée e e

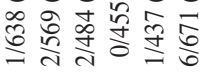

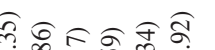

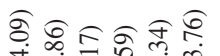

के

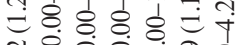

o e e e

‥8.8. 8.4

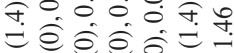

बे ơ

वे.

ध 8.8 . 8 .

$\infty$ o e e

-8.8. 8 -

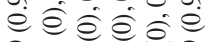

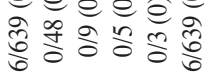

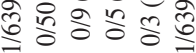

Fnm

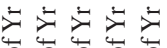

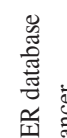

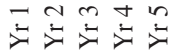

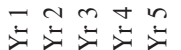

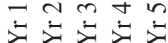

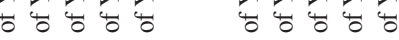

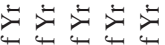

年

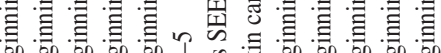

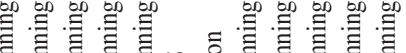

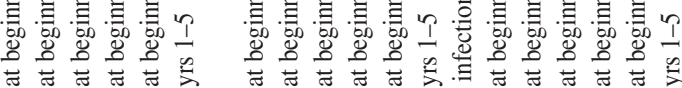

80

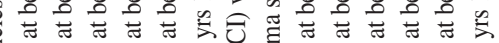

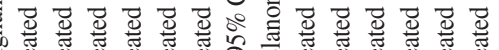

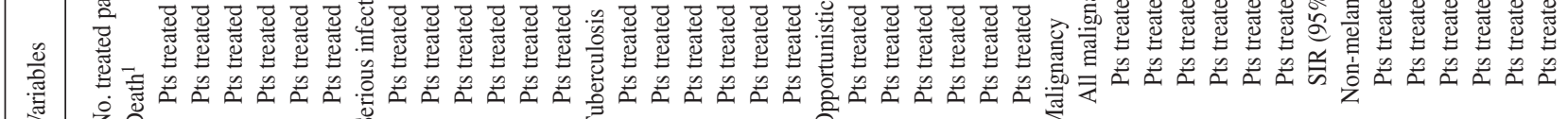




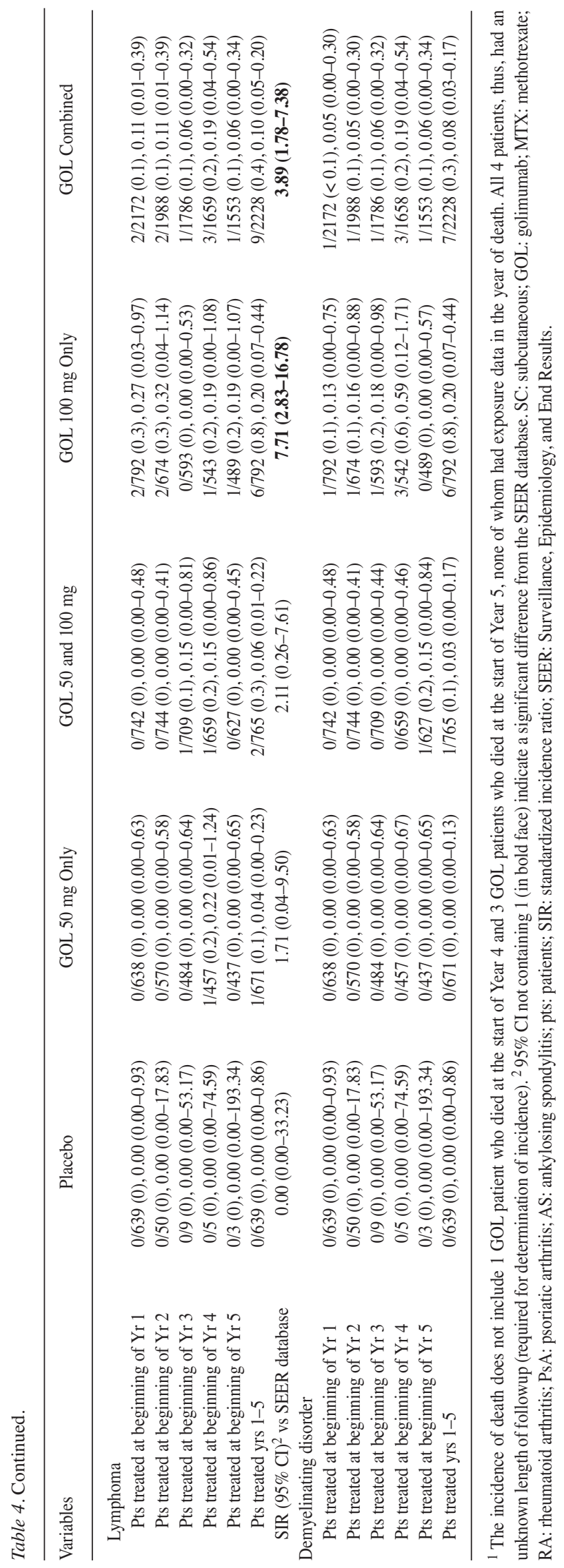

through weeks 24-52) and uncontrolled study periods. In addition to overall $\mathrm{AE}$ and $\mathrm{SAE}$, the incidence of $\mathrm{AE}$ of special interest (serious infections including opportunistic infections and TB, deaths, malignancies, and demyelination) per 100 pt-yrs was determined.

Patient retention was substantial, with about $60 \%$ of patients with RA, 69\% with PsA, and $72 \%$ with AS completing 5 years of followup, reflecting the sustained efficacy observed through up to 5 years of GOL treatment ${ }^{10,14,17,21,24}$. This retention, which compares favorably with 5- and 10-year drug survival rates for $\mathrm{ETN}^{29}$ and $\mathrm{ADA}^{30}$, respectively, allowed for the analysis of 2228 patients with a mean of 203 weeks of GOL safety followup.

The most common AE included infections, constitutional symptoms, HTN, injection site erythema, and elevated ALT levels. Only 1 ISR led to discontinuation of study drug. These findings were consistent with those observed through 5 years of $\mathrm{ETN}^{29}$ and 10 years of $\mathrm{ADA}^{30}$ treatment in patients with RA.

While there were numerically more $\mathrm{AE}$ and SAE; cases of TB, demyelination, and ISR; and deaths in the GOL than placebo groups, when adjusted for duration of followup, there were no significant differences between GOL and placebo for the incidence of serious infection, active TB, opportunistic infection, death, demyelination, or malignancy. In addition, the occurrence of these $\mathrm{AE}$ did not increase over time. A higher incidence of lymphoma relative to the general US population, however, was observed through 5 years among patients who received GOL $100 \mathrm{mg}$ only, and as a result, also among all GOL-treated patients. Patients with RA largely drove this higher incidence of lymphoma. Among the 8 patients with RA who had lymphoma, disease duration averaged 12.7 years (compared with 7.6 yrs for all the overall safety population assessed ${ }^{7}$ and baseline DAS28-CRP scores averaged 6.2 (compared with 5.7 for all other patients with RA). This indicates longstanding active disease, an important consideration given that patients with RA have a higher lymphoma risk than the general population ${ }^{31}$ and this risk increases with longer disease duration and disease activity ${ }^{32,33}$. While most lymphomas developed in patients who received GOL $100 \mathrm{mg}$, as reported $^{7}$, this may be expected given the possibility of dose escalation from $50 \mathrm{mg}$ to $100 \mathrm{mg}$ in patients with persistently active disease and the longer exposure of a greater number of patients to the $100-\mathrm{mg}$ dose. Only 2 patients with lymphoma had evidence of EBV infection, which is noteworthy because the rate of EBV infection is higher among patients with lymphoma associated with immunosuppressive therapy than among patients with other lymphomas ${ }^{34}$. While lymphoma is a known, albeit infrequent, $\mathrm{AE}$ that was observed in these studies that were not powered to detect statistical significance of the differential rates of rare $\mathrm{AE}$ across dose groups, the potential development of lymphoma with higher doses of GOL requires continued pharmacovigilance.

Personal non-commercial use only. The Journal of Rheumatology Copyright @ 2016 . All rights reserved. 


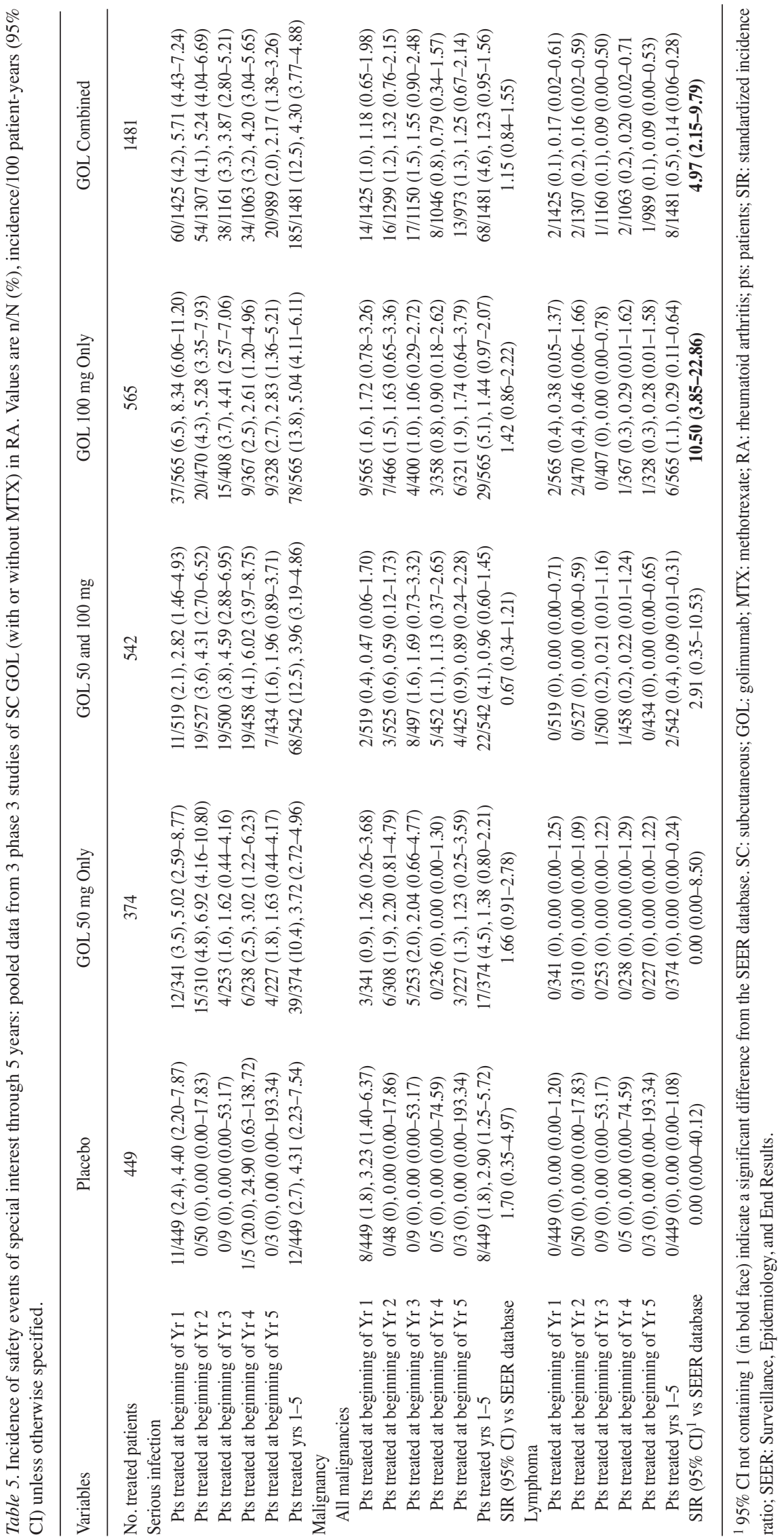

Personal non-commercial use only. The Journal of Rheumatology Copyright (c) 2016. All rights reserved. 
As a limitation to these analyses, the length of placebo followup was relatively short and there was no longterm control group. However, it would have been unethical to continue giving patients in the control group placebo for 5 years. The designs of these clinical trials, which incorporated an early escape option and dose escalation during open-label extension, confound definitive attribution of $\mathrm{AE}$ to a single GOL dose in some patients. The ability to adjust the use of concomitant medications during the open-label study extensions also confounds the analyses. Nevertheless, observing 2228 patients treated with GOL over 5 years with 8702 pt-yrs of followup provides considerable insight into the longterm safety profile of GOL.

\section{ACKNOWLEDGMENT}

The authors thank Michelle Perate, MS, and Mary Whitman, PhD, (Janssen) for writing and editorial support, and Stephen Xu, MS, (Janssen) for data analysis support.

\section{ONLINE SUPPLEMENT}

Supplementary data for this article are available online at jrheum.org.

\section{REFERENCES}

1. Janssen Biotech, Inc. Simponi (golimumab) injection, for subcutaneous use. Highlights of prescribing information. [Internet. Accessed September 29, 2016.] Available from: www.simponi.com/shared/product/simponi/ prescribing-information.pdf

2. European Medicines Agency. Simponi (golimumab). Summary of product characteristics. [Internet. Accessed September 6, 2016.] Available from: www.ema.europa.eu/docs/en_GB/ document_library/EPAR_-_Product_Information/human/000992/ WC500052368.pdf

3. AbbVie, Inc. Humira (adalimumab) injection, for subcutaneous use. Highlights of prescribing information. [Internet. Accessed September 6, 2016.] Available from: www.rxabbvie.com/pdf/humira.pdf

4. UCB, Inc. Cimzia (certolizumab pegol), lyophilized powder or solution for subcutaneous use. Highlights of prescribing information. [Internet. Accessed September 29, 2016.] Available from: www.cimzia.com/assets/pdf/Prescribing_Information.pdf

5. Immunex Corporation. Enbrel (etanercept), solution for subcutaneous use. Highlights of prescribing information. [Internet. Accessed September 29, 2016.] Available from: pi.amgen.com/united_states/enbrel/derm/enbrel_pi.pdf

6. Janssen Biotech, Inc. Remicade (infliximab), lyophilized concentrate for intravenous injection. Highlights of prescribing information. [Internet. Accessed September 6, 2016.] Available from: www.remicade.com/shared/product/remicade/ prescribing-information.pdf

7. Kay J, Fleischmann R, Keystone E, Hsia EC, Hsu B, Mack M, et al Golimumab 3-year safety update: an analysis of pooled data from the long-term extensions of randomised, double-blind, placebo-controlled trials conducted in patients with rheumatoid arthritis, psoriatic arthritis or ankylosing spondylitis. Ann Rheum Dis 2015;74:538-46.

8. Emery P, Fleischmann RM, Moreland LW, Hsia EC, Strusberg I, Durez P, et al. Golimumab, a human anti-tumor necrosis factor alpha monoclonal antibody, injected subcutaneously every four weeks in methotrexate-naive patients with active rheumatoid arthritis: twenty-four-week results of a phase III, multicenter, randomized, double-blind, placebo-controlled study of golimumab before methotrexate as first-line therapy for early-onset rheumatoid arthritis. Arthritis Rheum 2009;60:2272-83.

9. Emery P, Fleischmann RM, Doyle MK, Strusberg I, Durez P, Nash $\mathrm{P}$, et al. Golimumab, a human anti-tumor necrosis factor monoclonal antibody, injected subcutaneously every 4 weeks in patients with active rheumatoid arthritis who had never taken methotrexate: 1-year and 2-year clinical, radiologic, and physical function findings of a phase III, multicenter, randomized, double-blind, placebo-controlled study. Arthritis Care Res 2013;65:1732-42.

10. Emery P, Fleischmann RM, Strusberg I, Durez P, Nash P, Amante E, et al. Efficacy and safety of subcutaneous golimumab in methotrexate-naive patients with rheumatoid arthritis: five-year results of a randomized clinical trial. Arthritis Care Res 2016;68:744-52.

11. Keystone EC, Genovese MC, Klareskog L, Hsia EC, Hall ST, Miranda PC, et al. Golimumab, a human antibody to tumour necrosis factor $\alpha$ given by monthly subcutaneous injections, in active rheumatoid arthritis despite methotrexate therapy: the GO-FORWARD Study. Ann Rheum Dis 2009;68:789-96.

12. Keystone E, Genovese MC, Klareskog L, Hsia EC, Hall S, Miranda $\mathrm{PC}$, et al. Golimumab in patients with active rheumatoid arthritis despite methotrexate therapy: 52-week results of the GO-FORWARD study. Ann Rheum Dis 2010;69:1129-35.

13. Keystone EC, Genovese MC, Hall S, Miranda PC, Bae SC, Palmer $\mathrm{W}$, et al. Golimumab in patients with active rheumatoid arthritis despite methotrexate therapy: results through 2 years of the GO-FORWARD study extension. J Rheumatol 2013;40:1097-103.

14. Keystone EC, Genovese MC, Hall S, Bae SC, Han C, Gathany TA, et al. Safety and efficacy of subcutaneous golimumab in patients with active rheumatoid arthritis despite methotrexate therapy: final 5 -year results of the GO-FORWARD trial. J Rheumatol 2015;43:298-306.

15. Smolen JS, Kay J, Doyle MK, Landewé R, Matteson EL, Wollenhaupt J, et al; GO-AFTER study investigators. Golimumab in patients with active rheumatoid arthritis after treatment with tumour necrosis factor alpha inhibitors (GO-AFTER study): a multicentre, randomised, double-blind, placebo-controlled, phase III trial. Lancet 2009;374:210-21.

16. Smolen JS, Kay J, Landewé RB, Matteson EL, Gaylis N, Wollenhaupt $\mathrm{J}$, et al. Golimumab in patients with active rheumatoid arthritis who have previous experience with tumour necrosis factor inhibitors: results of a long-term extension of the randomised, double-blind, placebo-controlled GO-AFTER study through week 160. Ann Rheum Dis 2012;71:1671-9.

17. Smolen JS, Kay J, Doyle M, Landewé R, Matteson EL, Gaylis N, et al. Golimumab in patients with active rheumatoid arthritis after treatment with tumor necrosis factor $\alpha$ inhibitors: findings with up to five years of treatment in the multicenter, randomized, double-blind, placebo-controlled, phase 3 GO-AFTER study. Arthritis Res Ther 2015;17:14.

18. Kavanaugh A, McInnes I, Mease P, Krueger GG, Gladman D, Gomez-Reino J, et al. Golimumab, a new human tumor necrosis factor alpha antibody, administered every four weeks as a subcutaneous injection in psoriatic arthritis: Twenty-four-week efficacy and safety results of a randomized, placebo-controlled study. Arthritis Rheum 2009;60:976-86.

19. Kavanaugh A, van der Heijde D, McInnes IB, Mease P, Krueger GG, Gladman DD, et al. Golimumab in psoriatic arthritis: one-year clinical efficacy, radiographic, and safety results from a phase III, randomized, placebo-controlled trial. Arthritis Rheum 2012;64:2504-17.

20. Kavanaugh A, McInnes IB, Mease PJ, Krueger GG, Gladman DD, van der Heijde D, et al. Clinical efficacy, radiographic and safety

Personal non-commercial use only. The Journal of Rheumatology Copyright @ $\odot 2016$. All rights reserved 
findings through 2 years of golimumab treatment in patients with active psoriatic arthritis: results from a long-term extension of the randomised, placebo-controlled GO-REVEAL study. Ann Rheum Dis 2013;72:1777-85.

21. Kavanaugh A, McInnes IB, Mease P, Krueger GG, Gladman D, van der Heijde D, et al. Clinical efficacy, radiographic and safety findings through 5 years of subcutaneous golimumab treatment in patients with active psoriatic arthritis: results from a long-term extension of a randomised, placebo-controlled trial (the GO-REVEAL study). Ann Rheum Dis 2014;73:1689-94.

22. Inman RD, Davis JC Jr, Heijde Dv, Diekman L, Sieper J, Kim SI, et al. Efficacy and safety of golimumab in patients with ankylosing spondylitis: results of a randomized, double-blind, placebo-controlled, phase III trial. Arthritis Rheum 2008; 58:3402-12.

23. Braun J, Deodhar A, Inman RD, van der Heijde D, Mack M, Xu S, et al. Golimumab administered subcutaneously every 4 weeks in ankylosing spondylitis: 104-week results of the GO-RAISE study. Ann Rheum Dis 2012;71:661-7.

24. Deodhar A, Braun J, Inman RD, van der Heijde D, Zhou Y, Xu S, et al. Golimumab administered subcutaneously every 4 weeks in ankylosing spondylitis: 5-year results of the GO-RAISE study. Ann Rheum Dis 2015;74:757-61

25. Felson DT, Anderson JJ, Boers M, Bombardier C, Furst D, Goldsmith C, et al. American College of Rheumatology. Preliminary definition of improvement in rheumatoid arthritis. Arthritis Rheum 1995;38:727-35.

26. van der Linden S, Valkenburg HA, Cats A. Evaluation of diagnostic criteria for ankylosing spondylitis. A proposal for modification of the New York criteria. Arthritis Rheum 1984;27:361-8.

27. Garrett S, Jenkinson T, Kennedy LG, Whitelock H, Gaisford P, Calin A. A new approach to defining disease status in ankylosing spondylitis: the Bath Ankylosing Spondylitis Disease Activity Index. J Rheumatol 1994;21:2286-91

28. National Cancer Institute: Surveillance, Epidemiology, and End Results. Overview of the SEER program. [Internet. Accessed September 6, 2016.] Available from: SEER.cancer.gov/about/overview.html

29. Klareskog L, Gaubitz M, Rodriguez-Valverde V, Malaise M, Dougados M, Wajdula J; Etanercept Study 301 Investigators Assessment of long-term safety and efficacy of etanercept in a 5-year extension study in patients with rheumatoid arthritis. Clin Exp Rheumatol 2011;29:238-47.

30. Furst DE, Kavanaugh A, Florentinus S, Kupper H, Karunaratne M, Birbara CA. Final 10-year effectiveness and safety results from study DE020: adalimumab treatment in patients with rheumatoid arthritis and an inadequate response to standard therapy. Rheumatology 2015;54:2188-97.

31. Smitten AL, Simon TA, Hochberg MC, Suissa S. A meta-analysis of the incidence of malignancy in adult patients with rheumatoid arthritis. Arthritis Res Ther 2008;10:R45.

32. Baecklund E, Ekbom A, Sparén P, Feltelius N, Klareskog L. Disease activity and risk of lymphoma in patients with rheumatoid arthritis: nested case-control study. BMJ 1998;317:180-1.

33. Baecklund E, Iliadou A, Askling J, Ekbom A, Backlin C, Granath F, et al. Association of chronic inflammation, not its treatment, with increased lymphoma risk in rheumatoid arthritis. Arthritis Rheum 2006;54:692-701.

34. Rosselet A, Vu DH, Meylan P, Chaubert AS, Schapira M, Pascual $\mathrm{M}$, et al. Associations of serum EBV DNA and gammopathy with post-transplant lymphoproliferative disease. Clin Transplant 2009;23:74-82. 